\title{
Comparison of Continental Seismic Velocities from Explosion Results and Laboratory Measurements
}

\author{
By \\ Toshi Asada \\ Geophysical Institute, University of Tokyo, \\ Tokyo, Japan
}

\begin{abstract}
The depth of the upper boundary of a layer in the crust, $h$, and its velocity, $V$, should have a relation like that obtained by a high pressure measurement of a rock. In this paper the values of $h$ and $V$ obtained by explosion seismological method are compared with $V$ and the pressure $P$ obtained by experiments. The ninety percents of $V$ and $h$ of the layers in which the velocities range from 5.9 to $6.3 \mathrm{~km} / \mathrm{sec}$ are in the domain corresponding to granitic rocks in a $V-P$ diagram.
\end{abstract}

Studies of the continental crust by the explosion seismological method have been improved very much in recent years. Models for crustal studies in many regions have been obtained. Most of the analyses were based on the assumption of the layered structure for the crust. Since a horizontal or dipped layer structure is assumed in most cases, the informations on crustal structures in various regions, or the mean velocities and the mean thicknesses of the layers, can be given in a tabular form. Most of such data before 1960 appear in Table I of the paper by SteinharT et al. (1960).*

The relation between pressure and velocities of various rocks have been studied by Birch (1960) and Hughes et al. A paper was written by Birci (1958) on the comparison of seismic velocities and laboratory measurements, and a similar problem was discussed by Kosminskaya et al. (1964). The purpose of the present paper is to compare

Table I.

\begin{tabular}{|c|c|c|c|c|c|c|c|c|c|c|c|c|c|}
\hline References & $V_{1}$ & $T_{1}$ & $V_{2}$ & $T_{2}$ & $V_{3}$ & $T_{3}$ & $V_{4}$ & $T_{4}$ & $V_{5}$ & $T_{5}$ & $V_{\mathrm{i}}$ & $T_{6}$ & Location \\
\hline 1 & 4.9 & 4.2 & 6.1 & 15. & 6.7 & & \multirow{8}{*}{5.8} & \multirow{8}{*}{9.9} & \multirow{8}{*}{6.1} & \multirow{8}{*}{15.5} & \multirow{8}{*}{6.7} & \multirow{8}{*}{20.} & \multirow{8}{*}{$\begin{array}{c}\text { Eastern N. Mex. } \\
\text { East Central Nev. } \\
\text { Eastern Colo. } \\
\text { Coast of Calif. } \\
\text { New test site to Ordway, Colo } \\
\text { Santa Monica Lake Mead } \\
\text { West Alps } \\
\text { Eastern Colo. }\end{array}$} \\
\hline 2 & 3.0 & 0.7 & 6.0 & 27. & & & & & & & & & \\
\hline 3 & 2.9 & 0.6 & 4.8 & 0.4 & 5.2 & 1.3 & & & & & & & \\
\hline 4 & 3.0 & 7.6 & 6.1 & 9.2 & 7.0 & 9.4 & & & & & & & \\
\hline 5 & 3.0 & 1.4 & 6.0 & 22.9 & 6.5 & 1.6 & & & & & & & \\
\hline 6 & 3.0 & 2.0 & 6.2 & 20. & 7.0 & 7. & & & & & & & \\
\hline 7 & 6.0 & 10 . & 7.4 & & & & & & & & & & \\
\hline 8 & 6.2 & 24. & 6.8 & 16. & & & & & & & & & \\
\hline
\end{tabular}

$V=$ velocity $(\mathrm{km} / \mathrm{sec})$

$T=$ thickness of layer $(\mathrm{km})$

1. Stewart and PAKISER (1962)

2. PAKISER and HILL

3. JACKSON et al.

4. HEALY
5. RYALL and STUART

6. ROLLER and HENLY

7. FuCHs et al.

8. ROLLER
(1963)

\footnotetext{
* Results after 1960 are given in Table $\mathrm{I}$.
} 
seismic velocities with laboratory measurements taking the assumption of layered structure into consideration and using many data available.

If a layer in the crust is composed of a certain kind of rock, the depth of the upper boundary of the layer, $h$, and the velocity in the layer, $V$, should have a relation just like that obtained by a high pressure measurement of a rock, because $h$ and the pressure are identifiable or the pressure at the depth, $h$, can be calculated provided the density of the crust is assumed. In this paper the density of the crust is assumed to be 2.8, a value accurate enough for the present discussion.

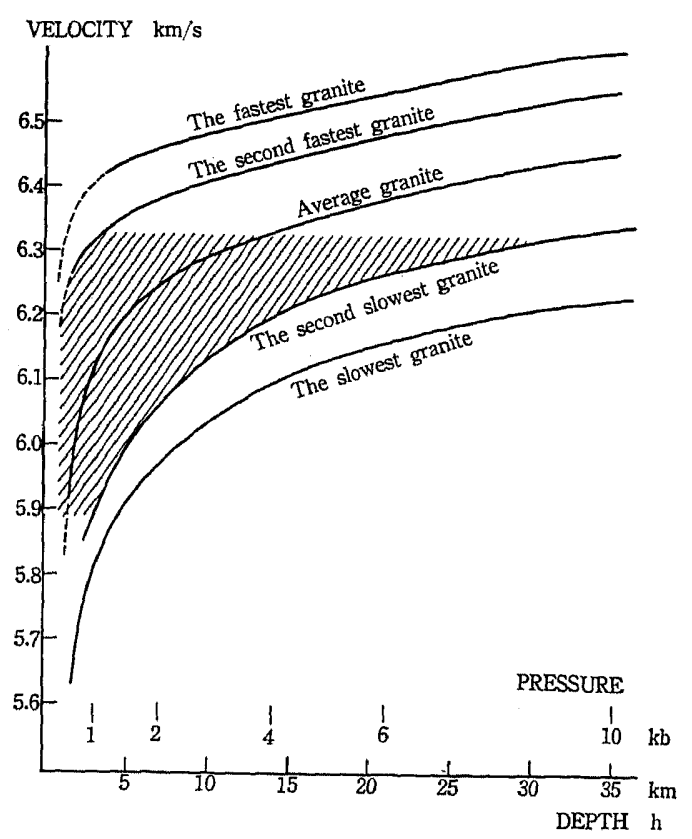

Fig. 1. Velocity depth relations for granites (F. BIRCH).

Fig. 1 shows the pressure velocity relations for granites obtained by BIRcH (1960). Taking $V$ as ordinate and $h$ as abscissa on this diagram, a point can represent a layer in a certain locality.

The layer in which the velocities are around $6.1 \mathrm{~km} / \mathrm{sec}$ has been regarded as granitic. If so, in order that the rocks of the layers are granitic, all points for these layers should be

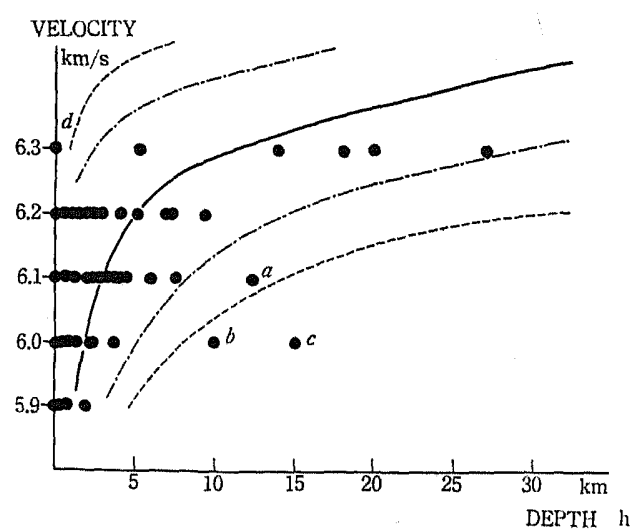

Fig. 2. Velocity depth diagram for the layers with velocities from 5.9 to $6.3 \mathrm{~km} / \mathrm{sec}$.

in the hatched domain of Fig. 1. In Fig. 2, $h$ and $V$ of the layers in which the velocities range from 5.9 to $6.3 \mathrm{~km} / \mathrm{sec}$ are shown. More than 90 per cent of all points are in the domain corresponding to the hatched area of Fig. 1. There are four exceptions: $a, b, c$, and $d$, corresponding respectively to eastern Colorado, the Black Sea, the Caspian Sea, and eastern New York State. As the velocity depth relation of most granitic rock is similar to that of granite, most of the layers in which the velocities are between 5.9 and $6.3 \mathrm{~km} / \mathrm{sec}$ may be regarded as granitic. In Fig. 2 the average relation between $h$ and $V$ for points, except $a, b, c$, and $d$, is quite similar to the velocity pressure relation for the average granite.

The velocity of the rock for layer $d$ is too high, and the velocities of the rocks for layer $b$ and $c$ are too low to be granitic. According to results of high-pressure experiments on rocks, no granite has such a low velocity as $6.0 \mathrm{~km} / \mathrm{sec}$ at the depth of $10 \mathrm{~km}$. Some sedimentary rocks at this depth have this low velocity.

Consequently, we may draw three different conclusions: (1) the layers at the three localities $b, c$, and $d$ are not composed of granitic rocks; (2) the model of crustal structures is wrong because of uncorrect analysis of data; (3) the temperature in $b$ and $c$ is much higher than the average temperature in other areas. The first conclusion is probably most 
likely and the last one impossible.

Two notes should be mentioned here. Since our present discussion is limited to the crustal problem, the effect of temperature is neglected. The depth from the surface to the upper boundary of the layer is considered to be the depth that corresponds to the pressure in the laboratory experiment; the depth from the surface to the middle of the layer is not adopted. That is, it is assumed that the velocity obtained from a time distance line

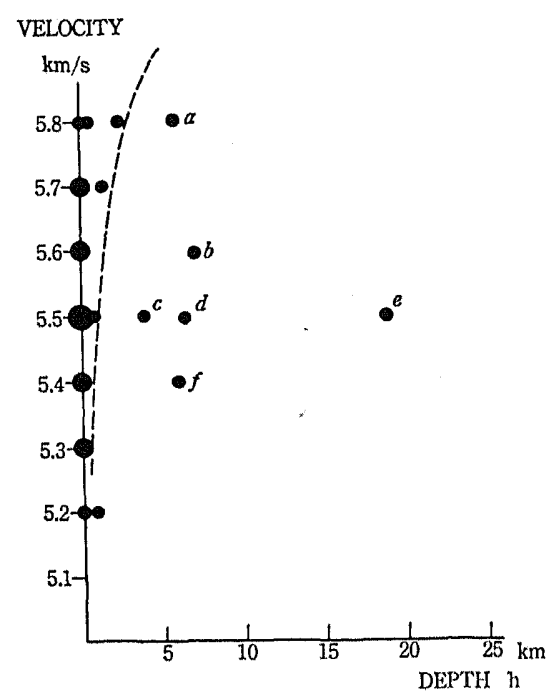

Fig. 3. Velocity depth diagram for the layers with velocities from 5.1 to $5.8 \mathrm{~km} / \mathrm{sec}$. is the velocity in the upper part of the layer, or that the vertical velocity gradient in the layer is not very large.

Fig. 3 is a diagram similar to Fig. 2, but the range of velocity is from 5.1 to 5.8 $\mathrm{km} / \mathrm{sec}$. The dashed line and the ordinate represent the boundaries for granitic rocks. In Fig. 3, six points are outside this area; the velocities for these six points are too low for the depth of the layers for the rock to be granitic. The rocks in these layers may be sedimentary, because some sedimentary rocks have lower velocities than granite under a pressure higher than 1000 bars. In Fig. 3, many points are in the domain for granite, and so some of the 5.5 $\mathrm{km} / \mathrm{sec}$ layers may be granitic. Even if they are, however, they may not be of the same kind of granitic rocks as those by which the $6.1 \mathrm{~km} / \mathrm{sec}$ layers are composed. If both are the same kind of granitic rocks, the velocity depth function should be continuous.

According to the results of high-pressure experiments, the velocity gradient for granites in the depth from 0 to $20 \mathrm{~km}$ is large enough to be detected by explosion seismological methods as understood from Fig. 1.

However, the time distance diagrams for the layers in which the velocity is around $5.5 \mathrm{~km} / \mathrm{sec}$ and the layers in which the velocity is around $6.1 \mathrm{~km} / \mathrm{sec}$ are usually com-

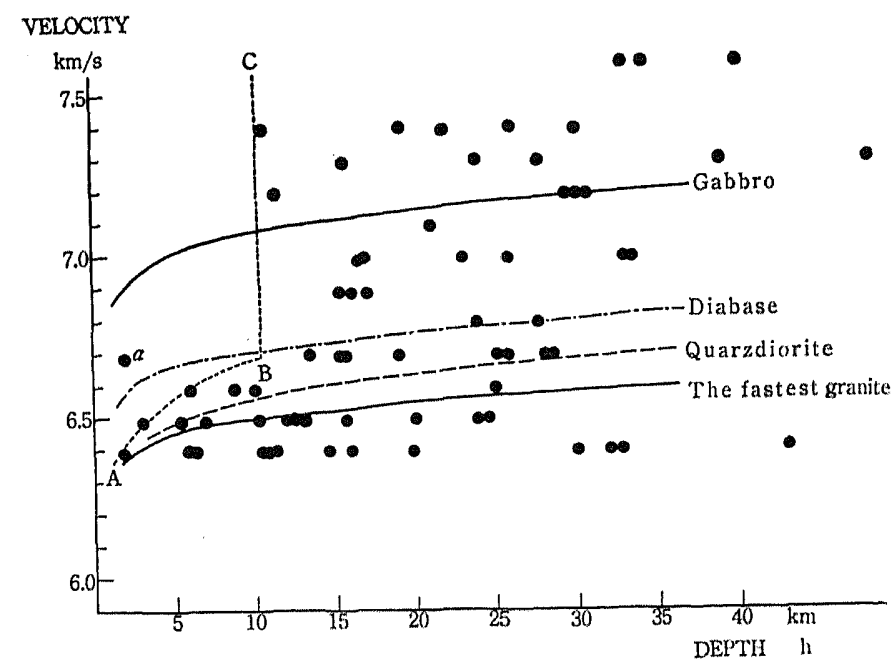

Fig. 4. Velocity depth diagram for the layers with velocities from 6.4 to $7.6 \mathrm{~km} / \mathrm{sec}$. 
posed of two lines and are different from the curves to be expected for such velocity gradients as are shown in Fig. 1. This consideration leads to the conclusion either that the boundary between those two layers is sharp in the velocity gradient or that the layers are composed of different materials.

The diagram for velocities from 6.4 to 7.6 $\mathrm{km} / \mathrm{sec}$ is given in Fig. 4. In this range of velocity, in the domain to the left of the dotted line $A B C$, there are no layers with one exception, $a$. The exception is for Iceland. In Fig. 4, the pressure velocity relations for quarzdiorite, diabase, and gabbro are shown, (BrRCH 1960), but the number of samples of each rock is not large enough to give the velocity depth relations for the fastest ones and the slowest ones, just like those of granites are shown in Fig. 1.

The essentials in the diagram in Fig. 4 are: (1) According to BIRCH (1958) the pressure velocity relation for the slowest diabase coincides with that for the fastest granite. The layers in which the velocity is $6.4 \mathrm{~km} / \mathrm{sec}$ may be of granitic rocks, (2) Usually the layers that are possibly composed of gabbro do not have their upper boundaries above $10 \mathrm{~km}$. (3) Some authors report that in some areas the velocities are between 7.0 and 7.7 $\mathrm{km} / \mathrm{sec}$ in the lower part of the crust. The velocities 7.6 and $7.7 \mathrm{~km} / \mathrm{sec}$ seem too high for the rock to be gabbro.

\section{References}

BIRCH, FRANCIS:

The velocity of compressional waves in rocks to 10 kilobars, 1, J. Geophys. Res., 65, 1084-1102, 1960.

BIRCH, FRANCIS:

Interpretation of the seismic structure of the crust in the light of experimental studies of wave velocities in rocks, Contributions in Geophysics in Honor of Beno Gutenberg, pp. 158-170, Pergamon Press, New York, 1958.

Fuchs, K., St. MÜLleR, E. Peterschmitt, J. P. ROTHÉ, A. STEIN and K. StrobaCh:

Krustenstruktur der Westalpen nach refractionsseismischen Messungen, Gerlands Beitr. Geophys., 72 (3), 149-169, 1963.

HEALY, J. H.:

Crustal structure along coast of California from seismic-refraction measurements, J. Geophys. Res., 68, 5777-5787, 1963.

JACKSON, W. H., S. W. STEWART and L. C. PAKISER: Crustal structure in eastern Colorado from seismicrefraction measurements, J. Geophys. Res., 68, 5767-5776, 1963.

KOSMINSKAYA, I. P. and Y. V. RIZNICHENKO:

Seismic studies of the earth's crust in Eurasia, Res. Geophys., 2, 81-122, 1964.

PAKISER, L. C. and D. P. HILL:

Crustal structure in Nevada and southern Idaho from nuclear explosion, J. Geophys. Res., 68, 5757-5766, 1963.

PAKISER, L. C. and J. S. STEINHART:

Explosion seismology in the western hemisphere, Res. Geophys., 2, 123-147, 1964.

Research Group for Explosion Seismology: Crustal structure in central Japan along longitudinal line $139^{\circ} \mathrm{E}$ as derived from explosion-seismic observation, Bull. Earthquake Res. Inst., 42, 515541, 1964.

Research Group for Explosion Seismology: Crustal structure in the western part of Japan, presented at meeting of Seismological Society of Japan, Oct. 1964.

Research Group for Niigata Aftershocks: Crustal study by observation of Niigata aftershocks along $139^{\circ} \mathrm{E}$ line, presented at the meeting of Seismological Society of Japan, May 1964.

ROLLER, J. C.:

Crustal structure in the eastern Colorado Plateau, Province from seismic refraction measurements, Bull. Seismological Society of America, 55, 107120, 1965.

ROLlER, JohN C. and JohN H. HEALY:

Seismic-refraction measurements of crustal structure between Santa Monica Bay and Lake Mead, J. Geophys. Res., 68, 5837-5849, 1963.

RYALl, Alan and DAvid J. StuART:

Travel times and amplitudes from nuclear explosions, Nevada Test Site to Ordway, Colorado, J. Geophys. Res., 68, 5821-5835, 1963.

Steinhart, J. S., R. Green, T. ASADA, A. RODRIGUEZ, B., L. T. ALDRICH and M. A. TUVE: The earth's crust, Carnegie Inst. Wash. Year Book, 61, 221-234, 1962.

STEINHART, J. S. and R. P. MEYER:

Explosion studies of continental structure, Carnegie Inst. Wash. Publ. 622, 1961.

SteWART, S. W. and L. C. PAKISER:

Crustal structure in eastern New Mexico interpreted from the Gnome explosion, Bull. Seismological Society of America, 52, 1017-1030, 1962. 